\title{
FARKLI BRANŞLARDAKI SPORCULARIN DENGE PERFORMANSLARININ KARŞILAŞTIRILMASI
}

\author{
Nurtekin ERKMEN ${ }^{1}$ Sibel SUVEREN ${ }^{2} \quad$ A.Salim GÖKTEPE ${ }^{3}$ \\ Kamil YAZICIOĞLU
}

\section{ÖZET}

Bu çalışmanın amacı: Farkıı yapısal özellikler taşıyan üç ayrı spor branşının gerektirdiği denge düzeylerini tespit etmek ve branşlara göre denge performanslarını karşılaştırmaktır. Çalışmaya, halen aktif olarak spor yapan ve araştırmaya gönüllü olarak katılmayı kabul 13 basketbolcu, 9 cimnastikçi ve 13 futbolcu olmak üzere toplam 35 erkek sporcu dahil edilmiştir. Deneklerin yaş, boy ve vücut ağırlığı ortalamaları sırasıyla: basketbolcularda $20.85 \mathrm{yıl}, 192.25 \mathrm{~cm}$ ve $87.85 \mathrm{~kg}$, cimnastikçilerde; 21.11 yıl, $173.44 \mathrm{~cm}$ ve 66.16 kg, futbolcularda; 21.31 yıl, $174.39 \mathrm{~cm}$ ve $70.07 \mathrm{~kg}$ 'dır. Denekler, son bir yıl içerisinde nörolojik hastalık, vestibüler-vizüel rahatsızlık veya son 6 ay içerisinde ciddi bir alt ekstremite sakatığı geçirmemiş bireylerden seçilmişlerdir.

Denge ölçümleri KAT 2000 (Kinesthetic Ability Trainer) ile gerçekleştirilmiştir. Her bir deneğin dominant, nondominant, çift bacak statik test ve dinamik test skorları olmak üzere toplam 4 ayrı denge ölçümü yapılmıştır. Verilerin istatistiksel analizleri SPSS for Windows 11.0 paket programında gerçekleştirilmiş ve anlamlıık seviyesi 0.05 olarak kabul edilmiştir. Dominant ve nondominant bacak statik denge test skoru ile boy ve vücut ağırığı arasında, çift bacak statik denge test skoru ile sadece vücut ağırlığı arasında anlamlı düzeyde bir korelasyon tespit edilmiştir $(p<0.05)$. Basketbol ve Cimnastik branşları arasında tüm denge testlerinde istatistiksel olarak anlamlı düzeyde farklılık tespit edilirken basketbol ve futbol branşları arasında çift bacak statik denge skorunda ve cimnastik ile futbol branşları arasında dinamik denge skorları anlamlı düzeyde farklı bulunmuştur $(p<0.05, p<0.01)$.

Sonuç olarak: Cimnastikçilerin denge performansının basketbolculara göre daha yüksek olduğu, futbolculara göre ise sadece dinamik denge performansının daha gelișmiş olduğu saptanmıştır. Futbolcuların denge performanslarının hem basketbolculara hem de cimnastikçilere yakın olduğu, basketbolcuların ve futbolcuların denge yetisi bakımından birbirine benzer özelliklere sahip oldukları belirlenmiştir.

Anahtar Kelimeler: Basketbol, Cimnastik, Futbol, Denge, KAT 2000.

\section{THE COMPARISON OF BALANCE PERFORMANCE OF THE ATHLETES WHO ARE IN DIFFERENT BRANCHES}

\section{ABSTRACT}

The aim of this study was to compare the balance parameters of the sportsmen who are in different branches. In this study, 13 basketball players, 9 gymnastics and 13 football players were included, who are still active players and volunteered to join. The average age, height and weights of the subjects were, in basketball players; 20.85 years, $192.25 \mathrm{~cm}$ and $87.85 \mathrm{~kg}$, in gymnastics; 21.11 years, $173,44 \mathrm{~cm}$ and $66.16 \mathrm{~kg}$, and in football players; 21.31 years, $174,39 \mathrm{~cm}$ and $70.07 \mathrm{~kg}$. None had any history of vestibular or neurological disease.

Dominant leg, nondominant leg, both leg static balance and dynamic balance measurements of the subjects were analyzed with KAT 2000 (Kinesthetic Ability Trainer) stabiliometer. SPSS for Windows 11.00 package program was used in the statistical evaluation of the datum. Level of significance was set at 0.05 . There was significant correlations between body mass and dominant leg static balance scores, body mass and nondominant leg balance scores, body mass and both legs balance scores, height and dominant leg balance sceres, height and nondominant leg balance scores $(p<0.05)$. No significant correlation were obtained among other parameters. According to the results the comparison of balance scores among the branches; dominant, nondominant, both leg static balance scores and dinamic balance scores were found in basketball and gymnastics branches as; $p<0.05$ meaning level. Both leg static balance scores was signifcantly different in basketball and football branches. The dynamic balance score was found in gymnastics - football branches different in meaning level $(p<0.05, p<0.01)$.

\footnotetext{
1 Selçuk Üniversitesi Beden Eğitimi ve Spor Yüksekokulu

2 Gazi Üniversitesi Beden Eğitimi ve Spor Yüksekokulu

3 Gülhane Askeri Tıp Akademisi Türk Silahlı Kuvvetleri Rehabilitasyon ve Bakım Merkezi
} 
As a result, it has been determined that the balance performances of the gymnastics were higher than basketball players. The performance of balance of gymnastics was found advanced according to the football players just in dynamic balance. It was seen that the balance performances of the football players are close not only to basketball players, but also to gymnastics, and basketball and football players had the similar features about the balance ability.

Key Words: Basketball, Gymnastics, Football, Balance Performance, KAT 2000.

\section{GiRiş VE AMAÇ}

Denge ve stabil bir postürü sürdürmek çoğu hareket uygulamalarının ayrılmaz bir parçasıdır (1). Denge kontrolü, duyusal girdilerin bütünleşmesi yanında esnek hareket şekillerinin planlanması ve uygulanmasını içeren kompleks bir motor yetenektir (2). Algılayıcı sistemlerden gelen bilgilerin integrasyonu, düzenleyici refleksif hareketlere izin veren uzayda postür kontrolünü sürdürmek için kişiye oryantasyonu hakkında bilgi sağlar (3). Ancak duyusal girdiler postural kontrolü sürdürmek için tek başına sorumlu değildir. Postural stabilite kas kitlesinin bütünlüğü, merkezi sinir sistemi içerisindeki sistemlerin etkinliği ve motor kontrol için eksiksiz sinirsel yollara bağlıdır (4).

Denge üzerindeki çevresel bileşenler somatosensoriyel, vizüel ve vestibüler sistemleri içerir. Merkezi sinir sistemi bu sistemlerden gelen çevresel girdileri birleştirir, vücut pozisyonu ve destek tabanı üzerinde postürü kontrol etmek için birçok uygun kassal cevapları seçer $(5,6)$. Denge, iyi bir performans için temel oluşturmakta ve kas, sinir sistemi içinde iletici olarak tanımlanmaktadır. Insanın denge sağlamadaki yeteneği, diğer motor sistemlerin gelişmesinde belirleyici bir faktör olarak tanımlanabilir (7).

Üst düzey sporcuların her bir disiplinin gerekleriyle bağlantılı olarak gelişen denge kontrolü sergiledikleri belirtilmektedir. Uzun bir zaman periyodunda bir spor öğrenme ve antrenman yapmak günlük yaşam aktivitelerinde dinamik ve statik postüral kontrolün etkinliğini geliştirir (8). Elit sporcular, branşlarının gereklerine göre postürü düzenlemek için kesin duyusal bilgiyi baskın olarak kullanırlar $(9,10)$. Örneğin tecrübeli cimnastikçilerde vücut oryantasyonu için somatosensoriyel işaretler, otolitik işaretlerden daha fazla bilgilendiricidir (11), oysa uzman dansçılarda postür düzenlenmesinde görme; güçlü bir unsurdur (12).

Postüral salınımın değerlendirilmesi spor tıbbında birçok potansiyel uygulamalara sahiptir (yetenekli sporcuları sınıflama, biyomekanik incelemeler, sporcu sakatlıklarının önlenmesi ve tedavinin izlenmesi). Cimnastik, basketbol gibi sporlarda, sporların gerektirdiği sabit bir postürde üstün yetenekli sporcuları seçme yöntemi olarak kullanılabileceği, ayrıca okçuluk gibi hedefleme sporlarında biyomekanik incelemelerde yararlanılabileceği belirtilmektedir (13). Ancak spor branşlarının gerektirdiği denge özelliklerini inceleyen ve farklı branştan sporcuların denge performanslarını karşılaştıran yeterli sayıda araştırma bulunmamaktadır. Bu çalışmada, farklı yapısal özellikler taşıyan üç ayrı spor branşının gerektirdiği denge düzeylerinin tespit edilmesi ve branşlara göre denge performanslarının karşılaştırıması amaçlanmıştır.

\section{MATERYAL VE YÖNTEM}

Çalışmaya, halen aktif olarak spor yapan ve araştırmaya gönüllü olarak katılmayı kabul eden 35 erkek sporcu katılmıştır. Araştırma grubu, 13'ü basketbol, 9'u cimnastik ve 13'ü de futbol branşından sporculardan seçilmiştir. Basketbolcular; 20.85 yıl yaş ortalaması, $192.25 \mathrm{~cm}$ boy ortalaması ve $87.85 \mathrm{~kg}$ vücut ağırığına, cimnastikçiler; 21.11 yıl yaş ortalaması, $173.44 \mathrm{~cm}$ boy ortalaması ve $66.16 \mathrm{~kg}$ vücut ağırığına, futbolcular; 21.31 yıl yaş ortalaması, $174.39 \mathrm{~cm}$ boy ortalaması ve 70.07 kg vücut ağırlığına sahiptiler. Araştırma grubu, son bir yıl içerisinde nörolojik hastalık, vestibülervizüel rahatsızlık veya son 6 ay içerisinde ciddi bir alt ekstremite sakatlığı geçirmemiş bireylerden seçilmişlerdir. Bu durum araştırma öncesinde bireylere verilen bir bilgi formu ile sorularak tespit edilmiştir. Ayrıca Araştırma grubuna, araştırmaya gönüllü olarak katıldıklarını belirten ve uygulanacak testler hakkında bilgilendirici bir belge sunulmuş ve bu belgenin okunarak imzalanması istenmiştir.

Araştırma, Gülhane Askeri Tıp Akademisi Türk Silahlı Kuvvetleri Rehabilitasyon ve Bakım Merkezi performans laboratuarında gerçekleştirilmiştir. Araştırmaya katılan sporcular hazırlık periyodunda teste alınmıştır.

\section{Denge Ölçümleri:}

Denge performansını tam olarak yansıtabilen stabilometre araçlarının bir versiyonu olan Kinesthetic Ability Trainer (KAT 2000, OEM Medical, Carlsbad, USA) denge sistemi kullanılarak denge testleri gerçekleştirilmiştir.

Araştırma grubu, önce hafif bir spor kıyafetiyle 5 dakika koşu bandı üzerinde ısındıktan sonra ve bir miktar esnetme yaptıktan sonra teste alınmışlardır. Postüral kontrol ölçümleri statik ve dinamik denge testini içermektedir. Statik denge testi; dominant bacak (tercih edilen bacak), nondominant bacak (tercih edilmeyen bacak) ve çift bacak duruş pozisyonlarında gerçekleştirilmiştir. Dinamik denge testi ise; çift bacak duruş pozisyonunda uygulanmıştır.

Test öncesinde Araştırma grubunun ölçüm aracına alışmaları ve öğrenme etkisini azaltmak amacıyla 3-5 dakika KAT 2000'de pratik yapmalarına izin verilmiştir. Bu esnada birey en iyi denge pozisyonunu belirlemiştir. Bu pozisyon kaydedilmiş ve bütün test edilen bireyler için kullanılmıştır. Testin tamamında araştırma grubu, kollarını göğüs üzerinde çapraz olarak tutarak, diz $20^{\circ}$ fleksiyona getirtilmiştir (14). Kolların göğüste birbirine çapraz olarak tutulması, kol 
pozisyonu ile ilgili balistik etkileri ortadan kaldırılır ve kişinin destek rayına temasla testte yanılma yapabilme şansını azaltır. Test süresince araştırma grubunun üst gövde kas hareketlerinin en aza indirilmesi ve sadece bacaklarını kullanarak testi tamamlaması teşvik edilmiştir (KAT 2000 kullanma kılavuzu). Eğer bir araştırma grubu, ölçüm sırasında dengesini sürdüremez ve parmaklıklara dokunursa test durdurulmuş ve tekrar edilmiştir (14). Denge testleri sırasında araştırma grubunun duruş pozisyonları bir fizyoterapist tarafından değerlendirilmiştir. Ölçüm sonucunda her bir denge testi için bir skor elde edilmiştir. Yüksek skorlar denge performansında azalmayı, düşük skorlar ise denge performansında artışı göstermektedirler.

\section{Statik Test:}

Statik test, sırasıyla dominant bacak, nondominant bacak ve her iki bacak üzerinde duruş pozisyonlarında gerçekleştirilmiştir. Bireylerin dominant bacağı, bir topa vururken hangi bacağını kullanırsın şeklinde bir soru yöneltilerek tespit edimliştir. Tek bacak statik testler sırasında diğer bacak 60-90 derece fleksiyonda ve platforma dokunmasına izin verilmemiştir. Denge sağlandığı anda bilgisayar ekranı kapatıımış ve araştırma grubundan KAT 2000'in önünde duvardaki daha önceden işaretlenmiş bir noktaya bakması istendikten sonra test başlatılmıştır. Test süresince bu pozisyonun korunması istenmiştir. Çift bacak statik test, ayakta durur pozisyonda iken yine tek ayak statik testte olduğu gibi gerçekleştirilmiştir (14).

\section{Dinamik Test:}

Dinamik denge testi, araştırma grubunun her iki ayağı üzerinde durması ile gerçekleştirilmiştir. Platformda y eksenine paralel ve $10.5 \mathrm{~cm}$ uzaklıkta çizgiler vardır. Optimal pozisyon, x ekseni üzerinde ayak uzun ekseninin en üst noktası ve merkezden eşit uzaklıkta, ayaklar omuz genişliğinde açık, bu çizgiler üzerine ayağın yerleştirilmesi ile elde edilmiştir. Pozisyon, araştırma grubu tarafından platformun öne, arkaya ve yanlara serbestçe hareket edeceek şekilde bulunmuştur. Doğru pozisyon için bilgisayar ekranından elde edilen görsel geri bildirim de kullanılmıştır. Birey bu testte, bilgisayar ekranındaki topun daire hareketi çizmesi ile oluşturulan referans pozisyonunu, platformu hareket ettirerek izlemiş ve test süresince bilgisayar ekranına bakmıştır (14). Test süresi sona erdiğinde test bilgisayar tarafından otomatik olarak bitirilmiştir.

\section{İstatistiksel Analiz:}

Verilerin istatistiksel değerlendirilmesinde SPSS for Windows 11.0 paket programı kullanılmıştır. Ölçümü yapılan değişkenlerin karşılaştırılmasında ortalama ve standart sapma değerleri kullanılmıştır.

Branşlar arası karşılaştırmalarda; normal dağılım gösteren değişkenler için One-way ANOVA ve post hoc testlerden LSD ve Dunnett $\mathrm{C}$, normal dağılım göstermeyen değişkenler için Kruskal-Wallis $H$ ve farklı grupların belirlenmesinde Mann-Whitney U testi uygulanmıştır. Parametreler arasındaki ilişkinin tespit edilmesinde, normal dağılım gösteren değişkenlerde Pearson Korelasyon analizi ve normal dağılım göstermeyen değişkenlerde Spearman Brown Sıra farkları korelasyon katsayısı kullanılmıştır. Tüm testler iki yönlü olarak uygulanmış ve sonuçlar 0.05 anlamlılık düzeyinde değerlendirilmiştir.

\section{BULGULAR}

Araştırma grubunu oluşturan tüm sporcuların yaş ortalaması $21.09 \pm 2.49$ yıl, boy uzunluğu ortalaması $180.78 \pm 11.03 \mathrm{~cm}$, vücut ağırlığı ortalaması $75.67 \pm 11.96 \mathrm{~kg}$ ve spor yaşı ortalaması $8.20 \pm 4.33$ yıl olarak tespit edilmiştir.

Tablo 1. Araştırma Grubunun Yaş, Boy, Vücut Ağırlığı ve Spor Yaşı Ortalama Değerleri

\begin{tabular}{|l|l|c|r|c|}
\hline Değişkenler & Spor Branşı & $\mathbf{n}$ & Ortalama & Std. Sapma \\
\hline \multirow{4}{*}{ Yaş (YıI) } & Basketbol & 13 & 20,85 & 2,70 \\
\cline { 2 - 5 } & Cimnastik & 9 & 21,11 & 2,52 \\
\cline { 2 - 5 } & Futbol & 13 & 21,31 & 2,43 \\
\cline { 2 - 5 } & Toplam & 35 & 21,09 & 2,49 \\
\hline \multirow{3}{*}{$\begin{array}{c}\text { Boy Uzunluğu } \\
\text { (cm) }\end{array}$} & Basketbol & 13 & 192,25 & 7,48 \\
\cline { 2 - 5 } & Cimnastik & 9 & 173,44 & 6,81 \\
\cline { 2 - 5 } & Futbol & 13 & 174,39 & 5,55 \\
\cline { 2 - 5 } & Toplam & 35 & 180,78 & 11,03 \\
\hline \multirow{3}{*}{$\begin{array}{l}\text { (kg) } \\
\text { Sput Ağırlığı }\end{array}$} & Basketbol & 13 & 87,85 & 8,10 \\
\cline { 2 - 5 } & Cimnastik & 9 & 66,16 & 7,09 \\
\cline { 2 - 5 } & Futbol & 13 & 70,07 & 6,59 \\
\cline { 2 - 5 } & Toplam & 35 & 75,67 & 11,96 \\
\hline \multirow{3}{*}{ Spor Yaşı (yıl) } & Basketbol & 13 & 7,15 & 2,94 \\
\cline { 2 - 5 } & Cimnastik & 9 & 11,89 & 4,73 \\
\cline { 2 - 5 } & Futbol & 13 & 6,69 & 3,97 \\
\cline { 2 - 5 } & Toplam & 35 & 8,20 & 4,33 \\
\hline
\end{tabular}


SPORMETRE Beden Eğitimi ve Spor Bilimleri Dergisi 2007, Cilt: V, Sayı: 3

Tablo 2. Araştırma Grubunun Denge Skorlarının Branşlara göre Ortalama ve Standart Sapma Değerlerinin Dağııımı

\begin{tabular}{|l|l|c|c|c|}
\hline \multicolumn{1}{|c|}{ Değişkenler } & Spor Branşı & N & Ortalama & Std. Sapma \\
\hline \multirow{4}{*}{$\begin{array}{l}\text { Dominant Bacak } \\
\text { Statik Denge Skoru }\end{array}$} & Basketbol & 13 & 454,62 & 162,65 \\
\cline { 2 - 5 } & Cimnastik & 9 & 218,11 & 83,83 \\
\cline { 2 - 5 } & Futbol & 13 & 344,00 & 201,44 \\
\cline { 2 - 5 } & Toplam & 35 & 352,71 & 184,68 \\
\hline \multirow{4}{*}{$\begin{array}{l}\text { Nondominant Bacak } \\
\text { Statik Denge Skoru }\end{array}$} & Basketbol & 13 & 516,25 & 222,27 \\
\cline { 2 - 5 } & Cimnastik & 9 & 291,44 & 102,94 \\
\cline { 2 - 5 } & Futbol & 13 & 397,39 & 162,88 \\
\cline { 2 - 5 } & Toplam & 35 & 411,29 & 191,53 \\
\hline \multirow{4}{*}{$\begin{array}{c}\text { Cift Bacak Statik } \\
\text { Denge Skoru }\end{array}$} & Basketbol & 13 & 487,69 & 227,56 \\
\cline { 2 - 5 } & Cimnastik & 9 & 233,78 & 77,26 \\
\cline { 2 - 5 } & Futbol & 13 & 315,46 & 166,85 \\
\cline { 2 - 5 } & Toplam & 35 & 358,43 & 201,77 \\
\hline \multirow{4}{*}{$\begin{array}{l}\text { Dinamik Denge } \\
\text { Skoru }\end{array}$} & Basketbol & 13 & 1132,15 & 221,59 \\
\cline { 2 - 5 } & Cimnastik & 9 & 818,67 & 174,30 \\
\cline { 2 - 5 } & Futbol & 13 & 1239,62 & 464,17 \\
\cline { 2 - 5 } & Toplam & 35 & 1091,46 & 359,51 \\
\hline
\end{tabular}

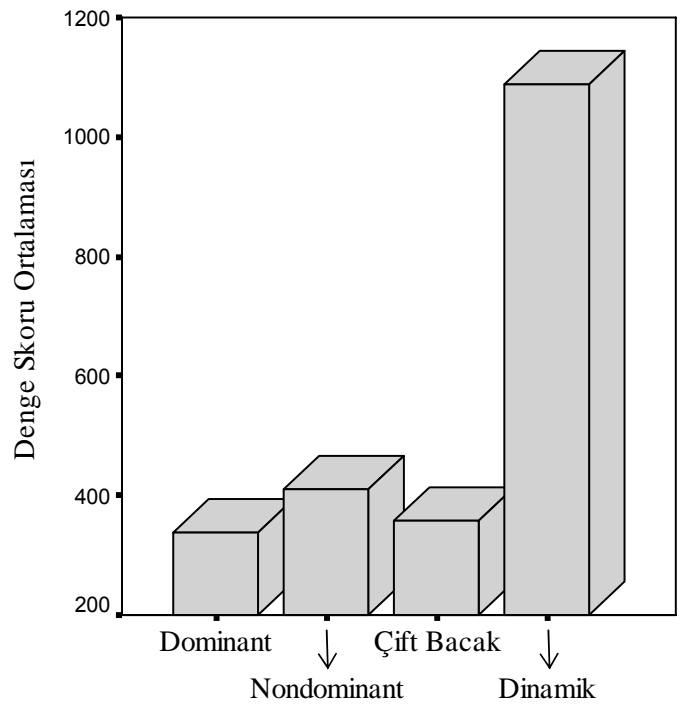

Grafik 1. Tüm Araştırma Grubunun Denge Skorları

Tablo 3. Araştırma Grubunun Yaş, Boy, Vücut Ağırlı̆̆ı ve Spor Yapma Süresi ile Denge Skorları Arasındaki Korelasyon Durumu

\begin{tabular}{|l|c|c|c|c|c|c|}
\hline \multicolumn{1}{|c|}{ Değişkenler } & \multirow{2}{*}{} & & Yaş & Boy & Vücut Ağırlığı & $\begin{array}{c}\text { Spor yapma } \\
\text { süresi }\end{array}$ \\
\hline $\begin{array}{l}\text { Dominant Bacak Statik } \\
\text { Denge Skoru }\end{array}$ & \multirow{2}{*}{35} & $\mathrm{r}$ &,- 062 &, $391^{*}$ &, $428^{*}$ &,- 194 \\
\cline { 3 - 7 } & & $\mathrm{p}$ &, 722 &, 020 &, 010 &, 263 \\
\hline $\begin{array}{l}\text { Nondominant Bacak Statik } \\
\text { Denge Skoru }\end{array}$ & \multirow{2}{*}{35} & $\mathrm{r}$ &,- 226 &, $408^{*}$ &, $389^{*}$ &,- 235 \\
\cline { 3 - 7 } & & $\mathrm{p}$ &, 199 &, 017 &, 023 &, 180 \\
\hline \multirow{2}{*}{ Çift Bacak Denge Skoru } & \multirow{2}{*}{35} & $\mathrm{r}$ &,- 020 &, 313 &, $445^{*}$ &,- 158 \\
\cline { 3 - 7 } & \multirow{2}{*}{35} & $\mathrm{p}$ &, 911 &, 067 &, 007 &, 365 \\
\hline \multirow{2}{*}{ Dinamik Denge Skoru } & $\mathrm{r}$ &, 016 &, 261 &, 276 &,- 172 \\
\cline { 3 - 7 } & $\mathrm{p}$ &, 928 &, 129 &, 108 &, 324 \\
\hline
\end{tabular}

${ }^{*} p<0.05$ 
ERKMEN, N., SUVEREN, S., GÖKTEPE, A.S., YAZICIOĞLU, K., "Farklı Branşlardaki Sporcuların Denge Performanslarının Karşılaştııılması"

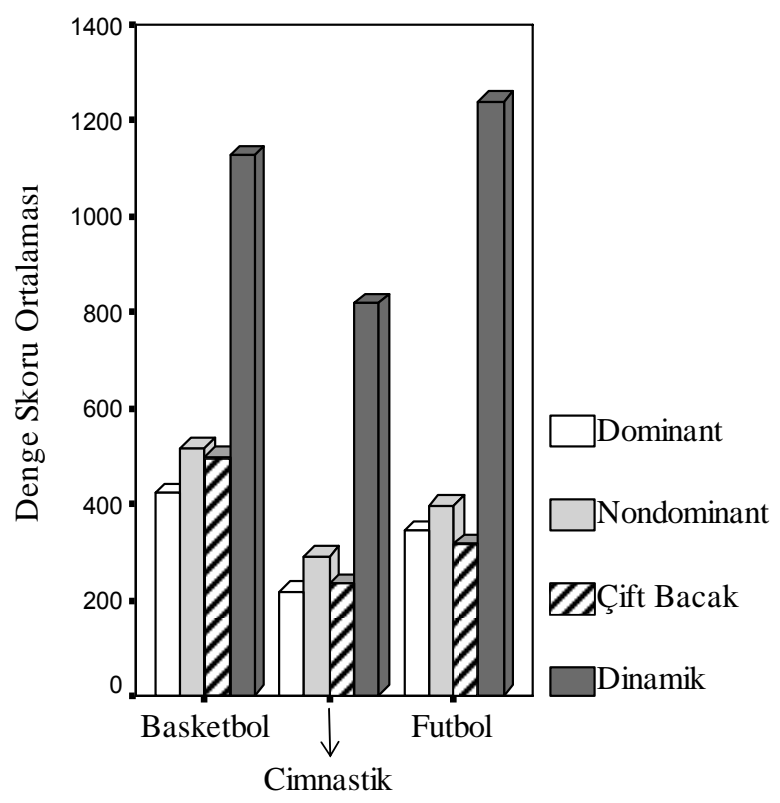

Grafik 2. Araştırma Grubunun Denge Skorlarının Branşlara göre Dağılımı

Tablo 4. Araştırma Grubunun Dominant Bacak Statik Denge Skorlarının Branşlar Arası Karşılaştırılması

\begin{tabular}{|c|c|c|c|c|c|c|c|}
\hline Değişkenler & Spor Branşı & $\mathbf{n}$ & Sıra Ortalaması & sd & $x^{2}$ & p & $\begin{array}{c}\text { Anlamlı } \\
\text { Fark }\end{array}$ \\
\hline \multirow{4}{*}{$\begin{array}{l}\text { Dominant Bacak } \\
\text { Statik Denge } \\
\text { Skoru }\end{array}$} & (b) Basketbol & 13 & 24,62 & \multirow[t]{4}{*}{2} & \multirow[t]{4}{*}{11,46} & \multirow[t]{4}{*}{, $003^{* *}$} & \multirow[t]{4}{*}{ b-c, } \\
\hline & (c) Cimnastik & 9 & 9,67 & & & & \\
\hline & (f) Futbol & 13 & 17,15 & & & & \\
\hline & Toplam & 35 & & & & & \\
\hline
\end{tabular}

${ }^{* *} \mathrm{P}<0.01$

Tablo 5. Araştırma Grubunun Nondominant Bacak Statik Denge Skorlarının Branşlar Arası Karşılaştırılması

\begin{tabular}{|c|c|c|c|c|c|c|c|}
\hline Değişkenler & Spor Branşı & $\mathbf{n}$ & Sıra Ortalaması & sd & $x^{2}$ & p & $\begin{array}{c}\text { Anlamlı } \\
\text { Fark }\end{array}$ \\
\hline \multirow{4}{*}{$\begin{array}{l}\text { Nondominant } \\
\text { Bacak Statik } \\
\text { Denge Skoru }\end{array}$} & (b) Basketbol & 13 & 22,83 & \multirow[t]{4}{*}{2} & \multirow[t]{4}{*}{7,36} & \multirow[t]{4}{*}{, $025 *$} & \multirow[t]{4}{*}{$b-c$} \\
\hline & (c) Cimnastik & 9 & 10,94 & & & & \\
\hline & (f) Futbol & 13 & 17,12 & & & & \\
\hline & Toplam & 35 & & & & & \\
\hline
\end{tabular}

${ }^{*} \mathrm{P}<0.05$

Tablo 6. Araştırma Grubunun Çift Bacak Statik Denge Skorlarının Branşlar Arası Karşılaştırılması

\begin{tabular}{|l|l|c|c|c|c|c|c|}
\hline \multicolumn{1}{|c|}{ Değişkenler } & \multicolumn{1}{|c|}{$\begin{array}{c}\text { Varyansın } \\
\text { Kaynağı }\end{array}$} & $\begin{array}{c}\text { Kareler } \\
\text { Toplamı }\end{array}$ & sd & $\begin{array}{c}\text { Kareler } \\
\text { Ortalaması }\end{array}$ & F & p & $\begin{array}{c}\text { Anlamlı } \\
\text { Fark }\end{array}$ \\
\hline $\begin{array}{l}\text { Çift Bacak } \\
\text { Statik Denge } \\
\text { Skoru }\end{array}$ & Gruplar Arası & 381059.0 & 2 & 190529.508 & 6.078 & $.006^{* *}$ & b-c, b-f \\
\cline { 2 - 8 } & Gruplar İ̧̧i & 1003176 & 32 & 31349.236 & & & \\
\cline { 2 - 8 } & Toplam & 1384235 & 34 & & & & \\
\hline
\end{tabular}

p $<0.01$ (Anlamlı farklılık varyansların eşit olduğu varsayımına dayalı olarak alınmıştır)

Tablo 7. Araştırma Grubunun Dinamik Denge Skorlarının Branşlar Arası Karşılaştırılması

\begin{tabular}{|c|l|c|c|c|c|c|c|}
\hline \multicolumn{1}{|c|}{ Değişkenler } & \multicolumn{1}{|c|}{$\begin{array}{c}\text { Varyansın } \\
\text { Kaynağı }\end{array}$} & $\begin{array}{c}\text { Kareler } \\
\text { Toplamı }\end{array}$ & Sd & $\begin{array}{c}\text { Kareler } \\
\text { Ortalaması }\end{array}$ & $\mathbf{F}$ & $\mathbf{p}$ & $\begin{array}{c}\text { Anlamlı } \\
\text { Fark }\end{array}$ \\
\hline \multirow{2}{*}{$\begin{array}{l}\text { Dinamik Denge } \\
\text { Skoru }\end{array}$} & Gruplar Arası & 976623.9 & 2 & 488311.958 & 4.078 & $.018^{*}$ & b-c, c-f \\
\cline { 2 - 9 } & Gruplar İ̧̧i & 3417717 & 32 & 106803.649 & & & \\
\cline { 2 - 9 } & Toplam & 4394341 & 34 & & & &
\end{tabular}

p $<0.05$ (Anlamlı farklııı varyansların eşit olmadığı varsayımına dayalı olarak alınmıştır) 
SPORMETRE Beden Eğitimi ve Spor Bilimleri Dergisi 2007, Cilt: V, Sayı: 3

Tablo 8. Araştırma Grubunun Denge Skorları Arasında Korelasyon Durumu

\begin{tabular}{|c|c|c|c|c|}
\hline Değişkenler & & $\begin{array}{l}\text { Nondominant Bacak } \\
\text { Statik Denge }\end{array}$ & Çift Ayak Denge & Dinamik Denge \\
\hline \multirow{2}{*}{$\begin{array}{l}\text { Dominant Bacak Statik } \\
\text { Denge }\end{array}$} & $r$ &, $451^{* *}$ &, $558^{* *}$ &, 532 ** \\
\hline & $p$ & ,007 & ,000 & ,001 \\
\hline \multirow{2}{*}{$\begin{array}{l}\text { Nondominant Bacak } \\
\text { Statik Denge }\end{array}$} & $r$ & &, $511^{* *}$ &, $370 *$ \\
\hline & $p$ & & ,002 & ,031 \\
\hline \multirow{2}{*}{ Çift Bacak Denge } & $r$ & & & ,392* \\
\hline & $p$ & & & ,020 \\
\hline
\end{tabular}

\section{TARTIŞMA VE SONUÇ}

Bu çalışmada; müsabaka süresi, zemini, motorik özelliklerin kullanılması gibi farklı özellikler taşıyan basketbol, cimnastik ve futbol branşlarından seçilen sporcuların denge parametrelerinin karşılaştırılması amaçlanmıştır.

Araştırma bulgularına göre; sporcuların yaş ortalamaları ve spor yaşı ortalamaları denge skorları ile karşılaştırıldığında anlamlı bir ilişkinin olmadığı belirlenmiştir. Boy uzunluğu ile dominant ve nondominant bacak statik denge skoru arasında, vücut ağırlığı ile dominant, nondominant ve çift bacak statik denge skoru arasında orta düzeyde pozitif bir ilişkinin olduğu tespit edilmiştir $(p<0.05)$.

Akgöl'ün (15), belirttiğine göre, Berger ve arkadaşları; insan vücudunun ters çevrilmiş bir sarkaca benzetilebileceğini ve vücudun ağırlık merkezinin destek yüzeyi içine düşürülerek dengenin sağlanabilmesi nedeniyle de kısa boylu bir kişide vücut ağırlık merkezinin izdüşümünün destek yüzeyi içine düşürülmesinin daha zor olduğunu bildirmişlerdir. Akgöl (15), değişik yaş gruplarında boy uzunluğu ve dengeyi karşılaştırmış ve uzun boylu kişilerin denge testlerinde daha başarılı olduklarını bildirmiştir. Bu sonuçlardan farklı olarak Era ve arkadaşları (16), kısa boy ve daha iyi denge arasında bir ilişki elde edilemediğini bildirmişlerdir. Özkan (17), Amerikan futbolu oyuncularında boy uzunluğu ile sadece sol bacak statik denge skoru arasında orta seviyede anlamlı negatif bir ilişki olduğunu, sağ bacak statik ve dinamik skor ile boy arasında anlamlı bir ilişki bulunmadığını bildirmiştir. Bu çalışmaya paralel olarak vücut ağırlığı ve denge arasında istatistiksel olarak anlamlı bir ilişki olmadığını belirten araştırmalar bulunmaktadır $(14,17)$.

Literatürde boy uzunluğu ve vücut ağırlığının denge parametreleri ile olan ilişkisini ayrıntılı olarak inceleyen araştırmalara rastlanmamıştır. Bu çalışmada boy uzunluğu arttıkça dominant ve nondominant statik denge skorlarının arttığı yani, kısa boylu sporcuların dengelerini sağlamada daha başarılı oldukları tespit edilmiştir. Bu sonuç, Era ve arkadaşlarının (16), sonuçlarıyla benzerdir. Ayrıca vücut ağırlığı arttıkça statik denge skorlarının da arttığı, vücut ağırığının artmasının denge performansını olumsuz yönde etkilediği belirlenmiştir.

Araştırma bulgularına göre; cimnastikçiler tüm denge testlerinde basketbolculardan daha yüksek performans göstermişlerdir $(p<0.05)$. Cimnastikçiler ve futbolcuların statik denge testilerindeki performansları birbirlerine benzer iken dinamik denge testi performansı cimnastikçilerde daha yüksek bulunmuştur $(p<0.05)$. Diğer taraftan futbolcular ve basketbolcuların denge performanslarında anlamlı farklılık yoktur.

Cimnastik antrenmanlarının yapısında statik ve dinamik dengeyi geliştirmeye yönelik çalışmaların daha çok yer alması, futbolda ise zeminin tam olarak düz olmaması ve bu zeminde dengenin sağlanabilmesi, saha ve diğer oyuncuların gözlemlenebilmesi için proprioseptif duyarlılığın daha gelişmiş olduğu sanılmaktadır. Diğer taraftan denge skorları ile boy uzunluğu ve vücut ağırlığı ortalamaları arasındaki tespit edilen pozitif ve orta düzeyde ilişki göz önünde bulundurulursa cimnastikçilerin basketbolculara göre daha kısa boylu ve vücut ağırlıklarının daha düşük olması bu sonuçların çıkmasında etkili olabilir.

Özkan (17), Amerikan futbol takımı oyuncularının denge performanslarını KAT 2000 ile ölçmüş, sağ statik denge skorunu 459.29, sol statik denge skorunu 498.18 ve dinamik denge skorunu 931.18 olarak bildirmiştir.

Bringoux ve arkadaşları (11), tarafından yapılan çalışmada, cimnastikçilerin vücut oryantasyonunu sağlamasında somatosensoriyel işaretlerin otholitik işaretlerden daha fazla bilgilendirici olduğu belirlenmiştir. Oysa dansçılarda postür düzenlenmesinde görmenin güçlü bir unsur olduğu belirtilmektedir (12). Paillard ve Noe (18), tarafından yapılan çalışmada ise amatör ve profesyonel futbol oyuncularının postüral kontrol performansı araştırılmış ve araştırma sonucunda; futbolun top, rakip ve takım arkadaşları hakkında güçlü bir görsel bağımlılığı meydana getirdiği, ayaklarla topu kontrol etme zorunluluğu, diğer oyuncuların yer değişimini izlemek zorunluluğuyla çelişen bir şekilde futbolcuların yere doğru bakmasını gerektirdiği bildirilmiştir. Bu yüzden, üst düzey futbol oyuncularının maçı gözlemleme zamanını arttırmak için bakışlarını toptan başka yöne çevirme becerileri gelişmiştir. Profesyonel futbol oyuncularında postüral kontrol için görmeye daha düşük bağımlılık, topu izlemeksizin kontrol etmek, bu yeteneği kazanmanın bir örneği olabileceği vurgulanmıştır. Üst düzey futbol oyuncularının, denge sürdürülürken topu kontrol etmek için proprioseptif 
kapasitelerinin gelişmiş olabileceği belirtilmiştir. Cote ve arkadaşları (19), postüral kontrol ve dinamik dengenin günlük yaşam aktivitelerinde ve spor aktivitelerinde optimum performans için gerekli olduğunu bildirilmişlerdir.

Vuilema ve Nougier (20), tarafından yapılan çalışmada; cimnastikçilerden oluşan araştırma grubunu, futbol ve hentbol oyuncularından oluşan bir kontrol grubu ile karşılaştırılmıştır. Tek ayak, çift ayak ve köpük yüzey üzerinde tek ayak olarak yaptığı denge ölçümlerinde iki grup arasında farklılık olmadığı bildirilmiştir. Ayrıca denge ölçümü yapılırken ilave olarak reaksiyon zamanı ölçümü uygulandığında, postüral görevin zorluğu arttığı için basınç merkezi yer değişimleri iki grupta da artmıştır. Görsel işaretler olduğu zaman postürü sürdürme performansının futbol ve hentbolcülerden oluşan kontrol grubuyla cimnastikçilerden oluşan araştırma grubunda farklı olmadığı bulunmuştur.

Perin ve arkadaşları (9), statik denge test performansını judo, dans ve kontrol grubu arasında karşılaştırmışlardır. Kontrol grubu ile judocuların değerleri arasında anlamlı farklılık tespit edilmemiştir. Görsel girdilerin engellendiği şartta ise judocular, dansçılardan anlamlı düzeyde daha yüksek performans göstermişlerdir. Çalışma sonucunda, yüksek seviyedeki sporcuların, her bir spor branşının gerekleriyle ilişkili olarak gelişen denge kontrolü sergiledikleri belirtilmiştir. Diğer bir araştırmada Stemm ve arkadaşları (21), golf oyuncularını 3 farklı handikap düzeyine göre sınıflandırmışlar ve postüral salınım düzeylerini incelemişlerdir. Bu çalışma sonucunda, başlangıç düzeyi ve yüksek handikap düzeyi arasında temel denge ölçümlerinde farklılık olmadığı bildirilmiştir.

Futbol oynayan ve oynamayan iki grubun denge parametrelerinin karşılaştırıldığı başka bir çalışma sonucunda; tüm denge parametrelerinin futbol oynayanlar lehine farklı çıktığı belirlenmiş, bu durum futbol oynayanlarda denge sağlayan fizyolojik sistemin daha iyi kontrole sahip olması şeklinde açıklanmıştır (22). Radford (23), profesyonel ve akademi futbol oyuncularının denge parametreleri arasında fark bulunmadığı tespit etmiştir. Paillard ve arkadaşları (24), farklı yarışma seviyelerine sahip 2 judocu grubun postüral kontrol performansında farklılık olmadığını, antrenmanlı judocuların mevcut görsel bilgisi, yarışma seviyesi arttığı için posturokinetik aktivitelerde daha önemli olabileceğini bildirmişlerdir.

Altay'ın (25), belirttiğine göre; Jastrejevskaya, dengenin sporsal becerilerde, iyi performans gösterenler ve göstermeyenler arasında ayrım yapılmasında bir etken olduğunu ve motor becerilerin sergilendiği bedensel gelişim için pozitif yönde bir ivme kazandırdığını bildirmiştir. Bu sonuçlara ek olarak; McGuine ve arkadaşları (26), basketbolcularda, Troop ve arkadaşları (27), futbolcularla yapmış oldukları çalışmalarda, zayıf dengenin ayak bileği sakatlığı için bir risk faktörü olarak tanımlanabileceğini vurgulamışlardır.

Bu çalışmada elde edilen denge skorlarının birbiriyle korelasyonu incelendiğinde tüm denge skorları arasında istatistiksel olarak anlamlı ilişkinin olduğu $(p<0.05$ ve $p<0.01)$ belirlenmiştir.

Gribble ve arkadaşları (28), bu çalışma sonucuna benzer olarak sağlıklı araştırma gruplarında sağ ve sol ekstremiteler arasında salınım mesafesinde anlamlı bir farklılık olmadığını bildirmişlerdir. Aydın ve arkadaşları (29), cimnastikçi ve kontrol grubunu gözler açık ve kapalı, yarı sert bir zeminde tek ayak dengede durma yeteneklerini karşılaştırdıkları çalışmalarında, cimnastikçilerin daha az hatayla dengede kalabildiklerini, hem cimnastikçi hem de kontrol grubunda dominant ve nondominant bacaklar arasında anlamlı fark olmadığını bildirmişlerdir.

Sonuç olarak: Spor branşları dikkate alınarak denge testleri ortalama değerleri incelendiğinde en iyi performansın cimnastikçilerde ve ardından futbolcularda görüldüğü anlaşılmaktadır. En düşük denge performansı ise basketbolcularda görülmüştür. Cimnastikçilerin denge yetisinin sadece dinamik dengede futbolculardan daha gelişmiş olduğu, statik dengeyi sürdürmede ise iki branş için de farklılık bulunmamıştır. Futbolcuların denge performanslarının hem basketbolculara hem de cimnastikçilere yakın olduğu, basketbolcuların ve futbolcuların denge yetisi bakımından birbirine benzer özelliklere sahip oldukları görülmektedir.

\section{KAYNAKLAR}

1. Carr, J.H., and Shepherd, R., Neurological Rehabilitation: Optimising Motor Performance, Oxford: Butterworth-Heineman, (1998).

2. Ferdjallah, M., Harris, G.F., Smith, P., Wertsch, J.J., Analysis of Postural Control Synergies During Quiet Standing in Healthy Children and Children with Cerebral Palsy, Clinical Biomechanics, 17, 203-210, (2002).

3. Cobb, S.V.G., Measurement of Postüral Stability Before and After Immersion in A Virtual Environment, Applied Ergonomics, 30, 47-57, (1999).

4. Horak, F.B., Shupert, C.L., Mirka, A.: Components of Postural Dyscontrol in The Elderly: A Review, Neurobiology of Aging, 10, 727-738, (1989).

5. Nashner, L.M., Black, F.O., Wall, C. III.: Adaptation to Altered Support and Visual Conditions During Stance: Patients with Vestibular Deficits, J Neurosci, 2, 536-544, (1982).

6. Shumway-Cook, A., Horak, F.B., Assessing The Influence of Sensory Interaction of Balance, Phys Ther, 66:10, 1548-1550, (1986).

7. Aksu, S., Denge Eğitiminin Etkilerinin Postüral Stres Testi ile Değerlendirilmesi, Hacettepe Üniversitesi Sağlık Bilimleri Enstitüsü Bilim Uzmanlığı Tezi, Ankara, (1994).

8. Perrin, P., Deviterne, D., Hugel, F., Perrot, C., Judo, Better Than Dance, Develops Sensorimotor Adaptabilities Involved in Balance Control, Gait and Posture, 15, 187-194, (2002). 
9. Perrin, P., Schneider, D., Deviterne, D., Perrot, C., Constantinescu, L., Training Improves The Adaptation to Changing Visual Conditions in Maintaining Human Posture Control in A Test of Sinusoidal Oscillation of The Support, Neurosci Lett, 245, 155-158, (1998).

10. Vuillerme, N., Danion, F., Marin, L., Boyadjian, A., Prieur, J.M., Weise, I., Nougier, V.: The Effect of Expertise in Gymnastics on Postural Control, Neurosci Lett, 303, 83-86, (2001).

11. Bringoux, L., Marin, L., Nougier, V., Barraud, P.A., Raphel, C., Effects of Gymnastics Expertise on The Perception of Body Orientation in The Pitch Dimension, J Vestib Res, 6, 251-258, (2000).

12. Golomer, E., Cremieux, J., Dupui, P., Isableu, B., OhImann, T., Visual Contribution to Self-Induced Body Sway Frequencies and Visual Perception of Male Professional Dancers, Neurosci Lett, 267, 189-192, (1999).

13. Rogind, H., Simonsen, H., Era, P., Bliddal, H., Comparison of Kistler 9861A Force Platform and Chattecx Balance System for Measurement of Postural Sway: Correlation and Test - Retest Reliability, Scand J Med Sci Sports, 13, 106-114, (2003).

14. Hansen, M.S., Dieckmann, B., Jensen, K., Jakobsen, B.W.: The Reliability Of Balance Tests Performed On The Kinesthetic Ability Trainer (KAT 2000), Knee Surg, Sports Traumatol, Arthrosc, $8: 180-185$, (2000).

15. Akgöl, A.C., Değişik Yaş Gruplarında Dengenin Değerlendirilmesi, Hacettepe Üniversitesi Sağlık Bilimleri Enstitüsü Bilim Uzmanlığı Tezi, Ankara, (1997).

16. Era, P., Schroll, M., Ytting, H., Gause-Nilsson, I., Heikkinen, E., Steen, B., Postural Balance and Its Sensory-Motor Correrelates in 75-Year-Old Men and Women: A Cross-National Comparative Study, J Gerontol, 51A: M53-M63, (1996).

17. Özkan, F., Amerikan Futbol Oyuncularında Spor Kıyafetinin Stabiliometri ve Sürat Performansı Üzerine Etkisi, Hacettepe Üniversitesi Sağık Bilimleri Enstitüsü Bilim Uzmanlığı Tezi, Ankara, (2002).

18. Paillard, T.H., Noe, F., Effect of Expertise and Visual Contribution on Postural Control in Soccer, Scand J Med Sci Sports, (2005).

19. Cote, K.P., Brunet, M.E., Gansneder, B.M., Shultz, S.J., Effects of Pronated and Supinated Foot Postures on Static and Dynamic Postural Stability, Journal of Athletic Training, 40:1, 41-46, (2005).

20. Vuillerme, N., Nougier, V., Attentional Demand for Regulating Postural Sway: The Effect of Expertise in Gymnastics, Brain Research Bulletin, 63, 161-165, (2004).

21. Stemm, J., Gren, L.B., Royer, T., An Investigation Of Motor Control: The Static And Dynamic Balance of Golfers, Journal of Athletic Training, 36:2 (Supplement), S-78, (2001).

22. Sucan, S., Yılmaz, A., Can, Y., Süer, C., Aktif Futbol Oyuncularının Çeşitli Denge Parametrelerinin Değerlendirilmesi, Erciyes Üniversitesi Sağlık Bilimleri Dergisi (Journal of Health Sciences) 14(1) 36-42, (2005).

23. Radford, D., A., Study of Balance in Elite and Academy Football Players, http://www.mds.qmw.ac.uk/sportsmed/research.shtml, (Erişim tarihi: 06.09.2006).

24. Paillard, T., Costes-Salon, C., Lafont, C., P Dupui, P., Are There Differences in Postural Regulation According to The Level of Competition in Judoists?, Br J Sports Med, 36, 304-305, (2002).

25. Altay, F., Ritmik Cimnastikte İki Farklı Hızda Yapılan Chaine Rotasyon Sonrasında Yan Denge Hareketinin Biyomekanik Analizi, Hacettepe Üniversitesi Sağlık Bilimleri Enstitüsü Doktora Tezi, Ankara, (2001).

26. McGuine, T.A., Greene, J.J., Best, T., Leverson, G.: Balance as A Predictor of Ankle Injuries in High School Basketball Players, Clinical Journal of Sport Medicine, 10, 239-244, (2000).

27. Troop, H., Ekstrand, J., Gillquist, J., Stabiliometry in Functional Instability of The Ankle and Its Value in Predicting Injury, Medicine and Science in Sports and Exercise, 16, 64-66, (1984).

28. Gribble, P.A., Hertel, J., Piegaro, A.B.: Predictors For Performance Of Dynamic Postural Control Using The Star Excursion Balance Test, Journal of Athletic Training, 36:2 (Supplement), S-77, (2001).

29. Aydın, T., Yıldız, Y., Yıldız, C., Ateşalp, S., Kalyon, T.A., Proprioception of The Ankle: A Comparison Between Teenaged Gymnastics and Controls, Foot Ankle Int, 23:2, 123-129, (2002). 